\title{
Anxiolytic and antidepressant potential of methanol leaf extract of Cassia singueana f. (fabaceae)
}

\author{
Alkali Yusuf Ibrahim $1{ }^{1}{ }^{*}$, Kabiru Abubakar ${ }^{1}$, Yerima Musa ${ }^{1}$, Aliyu Hamidu Ahmed ${ }^{2}$, Maryam Haruna Gada ${ }^{1}$ \\ and Fateema Yusuf Maitambari ${ }^{1}$
}

${ }^{1}$ Department of Pharmacology and Toxicology Usmanu Danfodiyo University, Sokoto, Nigeria.

2 Department of Pharmacognosy and Ethno-pharmacy Usmanu Danfodiyo University, Sokoto, Nigeria.

Publication history: Received on 29 March 2019; revised on 08 May 2019; accepted on 10 May 2019

Article DOI: https://doi.org/10.30574/gscbps.2019.7.2.0057

\begin{abstract}
Depression belongs to a class of mental health disorders termed affective disorders. Affective disorders are disorders related to mood rather than cognitive or thought disturbances. Anxiety is defined as an exaggerated feeling of apprehension, uncertainty and fear. It is an unpleasant state of tension with an anticipation of imminent danger. This research was aimed at evaluating the anxiolytic and antidepressant property of methanol leaf extract of Cassia singueana using Hole Board Test, Open field test, Force swim test and Tail suspension test. The anxiolytic activity was evaluated with adult mice using the hole-board test, elevated plus maze, and open field test. Thirty albino mice were used for each model at the dose of 100, 200 and $400 \mathrm{mg} / \mathrm{kg}$ extract for second, third and fourth group respectively. First group is negative control that received distilled water and fifth received $1 \mathrm{mg} / \mathrm{kg}$ diazepam. The antidepressant potential was evaluated using force swim test and tail suspension models. Thirty rats were used in each of the model, in which they were divided into five groups of six rats each. $2^{\text {nd }}, 3^{\text {rd }}$ and $4^{\text {th }}$ group received 100,200 , and $400 \mathrm{mg} / \mathrm{kg}$ extract respectively. The first group received distilled water and 5th group received Imipramine 10mg in both the two models. In the hole board test, the extract significantly $(\mathrm{p}<0.05)$ increased the number of head dips at $100 \mathrm{mg} / \mathrm{kg}$. At a dose of $200 \mathrm{mg} / \mathrm{kg}$ the extract prolonged the time spent in the open arm in the elevated plus maze. At the doses of 100 and 200 $\mathrm{mg} / \mathrm{kg}$, the extract increased the exploratory behavior in the open field test. In the forced swim and tail suspension test, Cassia singueana methanol leaf extract significantly reduced the duration of immobility of wistar rats. From this results obtained, it can be concluded Cassia singueana methanol leaf extract contained phytochemicals with possible anxiolytic and antidepressant activity.
\end{abstract}

Keywords: Antidepressant; Anxiolytics; Cassia singueana; Methanol extract; Exploratory behavior

\section{Introduction}

The single most important distinguishing characteristic of humans from other species of animals is brain function. Brain disorders or dysfunctions are a major concern to the human society, and a field in which pharmacological intervention plays a key role [1]. Depression belongs to a class of mental health disorders termed affective disorders. Affective disorders are disorders related to mood rather than cognitive or thought disturbances. Depression may range from a very mild condition, which borders on normality to a severe case of depression which when associated with hallucinations and delusions are referred to as psychotic [1].

About $12 \%$ of people are affected by an anxiety disorder in a given year, and between $5 \%$ and $30 \%$ are affected at one point in their life [2]. Anxiety is defined as an exaggerated feeling of apprehension, uncertainty and fear. It is an unpleasant state of tension with an anticipation of imminent danger [3]. The somatic manifestation of anxiety includes,

\footnotetext{
* Corresponding author

E-mail address: galilie050@gmail.com
} 
fatigue, dizziness, palpitation, headache, insomnia and excessive perspiration. It is associated with almost all mental disorder and frequently with physical illness. Anxiety disorders are one of the most common mental disorders [4, 5]. According to large population-based surveys, up to $33.7 \%$ of the population are affected by an anxiety during their lifetime. Substantial under recognition and under treatment of these disorders have been demonstrated. There is no evidence that the prevalence rates of anxiety have changed in the past years. In cross-cultural comparisons, prevalence rates are highly variable [6].Anxiety disorders follow a chronic course; however, there is a natural decrease in prevalence rates with older age. Anxiety disorders are highly comorbid with other anxiety disorders and other mental disorders [6].A medicinal plant is any plant, which in one or more of its organs, contains substances that can be used for therapeutic purposes, or which are precursors for chemo-pharmaceutical semi-synthesis [7].

Medicinal plants are widely used in non-industrialized societies, because they are readily available and cheaper than modern medicines. The annual global export value of 50,000 to 70,000 plants with suspected medicinal properties was estimated to be US $\$ 2.2$ billion in 2012 and in 2017 , the potential global market for botanical extracts and medicines was estimated at several hundred billion dollars [8]. Medicinal plants, also called medicinal herbs, have been discovered and used in diseases and herbivorous mammals. Numerous phytochemicals with potential or established biological activity have been identified. However, since a single plant contains widely diverse phytochemicals, the effects of using a whole plant as medicine are uncertain. Further, the phytochemical content and pharmacological actions, if any, of many plants having medicinal potential remain unassessed by rigorous scientific research to define efficacy and safety [8].

Plants have been used for medicinal purposes long before prehistoric period. Ancient Unani manuscripts, Egyptian papyrus and Chinese writings described the use of herbs. Evidence exists that Unani Hakims, Indian Vaids and European and Mediterranean cultures were using herbs for over 4000 years as medicine. Indigenous cultures such as Rome, Egypt, Iran, Africa and America used herbs in their healing rituals, while others developed traditional medical systems such as Unani, Ayurveda and Chinese Medicine in which herbal therapies were used systematically (NHP India, 2016). Number of traditional healers uses this plant for treatment of affective disorders. The prevalence of anxiety and depression is on the increase and the conventional anxiolytic and antidepressant agents are associated with number of side effects, this urges our interest to explore plant archives for discovery of safer and effective agents.

\section{Material and methods}

\subsection{Materials and Chemicals}

Imipramine (TOFRANIL®) Expiry date: February, 2022 ASSOS Pharmaceuticals, 5L glass beaker, Metal suspension bar $70 \mathrm{~cm}$, Thread, Distilled water, Cassia singueana methanol leaf extract, Diazepam, Hole board, Open filed Apparatus, Elevated maze plus.

\subsection{Experimental animals}

Wistar rats of both sexes (127-168 g) and mice (17-22 g) were used in the study. The animals were maintained in a cage, well ventilated at room temperature with access to food and water ad libitum. The animals were maintained in accordance with the rules governing the use of laboratory animals as accepted internationally. All the experimental protocols were approved by the university animal's ethics committee with approval number UDUS/PCL/PG001.

\subsection{Collection of plant material and Preparation of extract}

The plant was collected in Sokoto state, January, 2018. It was identified in the Department of Pharmacognosy and Ethnomedicine, Faculty of Pharmaceutical Sciences, Usmanu Danfodiyo University, Sokoto. The plant was shade dried. $500 \mathrm{~g}$ of the dried powder was subjected to cold maceration for 72 hours with $95 \%$ methanol. Whatmann filter paper was used in filtering the extract, which was then concentrated in water bath at $40^{\circ} \mathrm{C}$. The dried extract was then transferred into an air-tight container for storage.

\subsection{Elevated plus Maze model}

The method described by Lister [17] was adopted for this study. Thirty (30) mice were picked for the experiment. The mice were grouped into five (5) groups of six mice each. A Group was labeled as positive control and administered 1 $\mathrm{mg} / \mathrm{kg}$ of Diazepam via intra-peritoneal route. Thirty (30) minutes was given for the drug to exert its action, and then the mice were each put into the maze and observed over three (3) minutes. The next groups of mice were subjected to the same test after administering $100 \mathrm{mg} / \mathrm{kg}, 200 \mathrm{mgkg}, 400 \mathrm{mg} / \mathrm{kg}$ of $C$. singueana extract and distilled water (negative control) via oral route respectively. The parameters observed include; number of entry into open arm, number of entry into closed arm and time spent in the arms respectively. 


\subsection{Open field test model}

The method described by Kulkarni and Reddy [18] was adopted for this study. (30) mice were picked for the experiment. The mice were randomly grouped into five (5) groups of six members each. A Group was labeled as positive control and administered $1 \mathrm{mg} / \mathrm{kg}$ of Diazepam via intra-peritoneal route. Thirty (30) minutes was given for the drug to exert its action, and then the mice were each put into the open field device and observed over three (3) minutes. The next groups of mice were subjected to the same test after administering $100 \mathrm{mg} / \mathrm{kg}, 200 \mathrm{mg} / \mathrm{kg}, 400 \mathrm{mg} / \mathrm{kg}$ of $C$. singueana extract and distilled water (negative control) via oral route respectively. The parameters observed include; number of crossings across peripheral squares and number of crossings across central region.

\subsection{Hole board test model}

The method described by Takeda [12] was adopted for this study. Thirty (30) mice were picked for the experiment. The mice were grouped into five (5) groups labeled according to drug/dose of drug given. A Group was labeled as positive control and administered $0.5 \mathrm{mg} / \mathrm{kg}$ of Diazepam to each of the four mice in the group via intra-peritoneal route. About 30 minutes was given for the drug to exert its action, then the mice were each put on the board riddled with same-sized holes and observed over three (3) minutes. The next groups of mice were subjected to the same test after administering $100 \mathrm{mg} / \mathrm{kg}, 200 \mathrm{mgkg}, 400 \mathrm{mg} / \mathrm{kg}$ of $C$. singueana extract and distilled water (negative control) via oral route respectively. Number of head dips was observed.

\subsection{Force swim test}

In 1977, Porsolt described this model which is the frequently adopted model used for screening antidepressant like activity in mice [9]. The thirty animals were grouped into five (5) groups of six (6) animals each. The animals were moved from the animal house to the laboratory prior to the experiment in their cages and were allowed to adapt to the laboratory condition for 2 hours.

The rats were individually forced to swim in open chamber $(25 \times 15 \times 25 \mathrm{~cm})$ containing water to a height of $15 \mathrm{~cm}$ and maintained at room temperature. Each animal showed vigorous movement during initial 2 minutes period of the test. The duration of immobility was manually recorded during the next 4 minutes of the total 6 minutes testing period.

\subsection{Tail suspension test}

This model was first described by Steru in 1986. The animals were moved from the laboratory on the experiment day in their cages and were allowed to adapt to the laboratory for 2 hours. The mice were individually suspended to the edge of a stand $50 \mathrm{~cm}$ above the floor, by adhesive tape and placed approximately $1 \mathrm{~cm}$ from the tip of the tail. Each animal under test was both acoustically and visually isolated from other animals during the test. The total period of immobility was recorded manually for 6 minutes.

\subsection{Treatment doses}

The doses of methanol leaf extract of Cassia singueana administered to the treatment groups in which $100 \mathrm{mg} / \mathrm{kg}, 200$ $\mathrm{mg} / \mathrm{kg}$ and $400 \mathrm{mg} / \mathrm{kg}$ were given to groups $2^{\text {nd }}, 3^{\text {rd }}$ and $4^{\text {th }}$ group respectively orally. The first group received distilled water and $5^{\text {th }}$ group received Imipramine $10 \mathrm{mg} / \mathrm{kg}$ I.P. in both the force swim test and tail suspension models.

\subsection{Data analysis}

Results were expressed as mean \pm standard error of mean (SEM). Data analysis was performed using SPSS statistical software (version 2.0). Comparison between groups was made using analysis of variance and Kruskal-Wallis test where necessary. When statistical difference was obtained, a post hoc Dunnett's test was performed for multiple comparisons depending on nature of data. Values of $\mathrm{P}<0.05$ were considered statistically significant.

\section{Results}

\subsection{Effect of methanol leaf extract of Cassia singueana on hole board test for exploratory behavior in mice}

Cassia singueana extract caused significant $(\mathrm{p}<0.05)$ increase in number of head dips in mice administered with $100 \mathrm{mg} / \mathrm{kg}$ (Figure 1). 


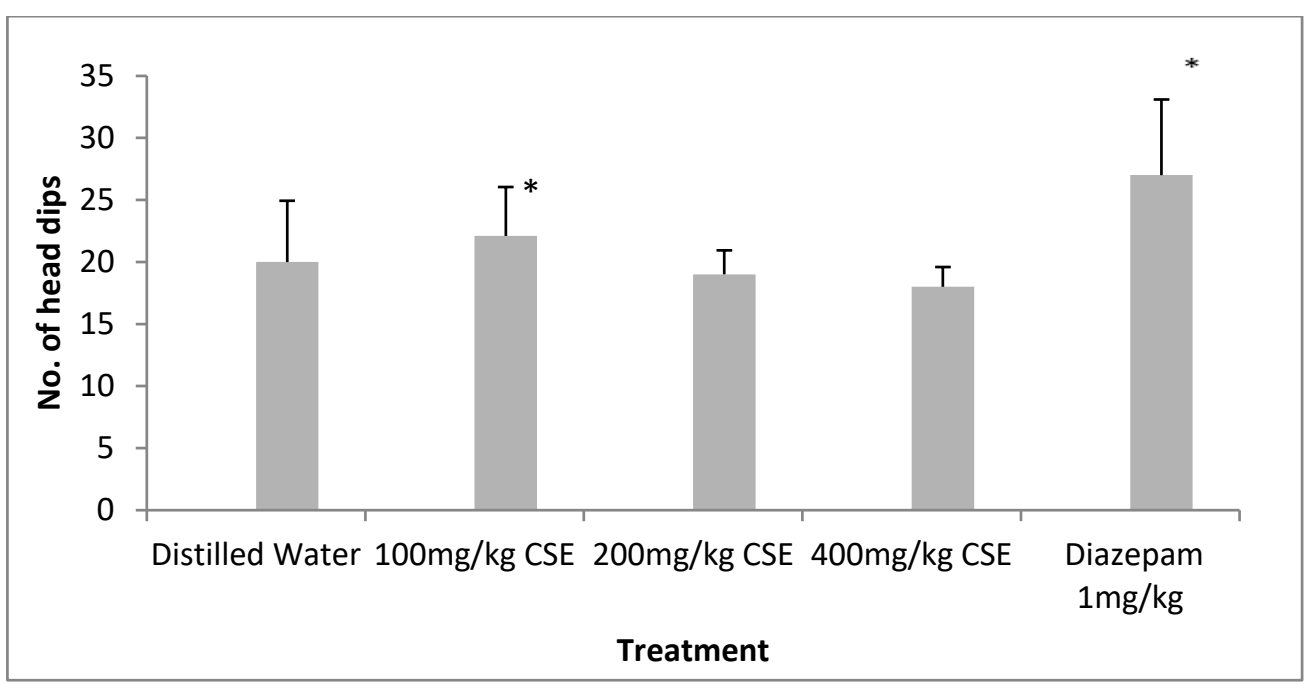

Figure1 Effect of methanol leaf extract of Cassia singueana on Hole Board Test for Exploratory behavior in mice. $*(\mathrm{p}<0.05)$ significance, Data presented as mean \pm standard error of mean. $n=6$, Dunnet post-hoc test

\subsection{Effect of methanol leaf extract of Cassia singueana on elevated plus maze test for exploratory behavior in mice}

Entry-wise, there is a higher rate of movement from the closed arm to the open arm and vice versa in the group of mice. The extract significantly increased the amount of time spent in the open arm at the dose of $200 \mathrm{mg} / \mathrm{kg}$ (Figure 2).

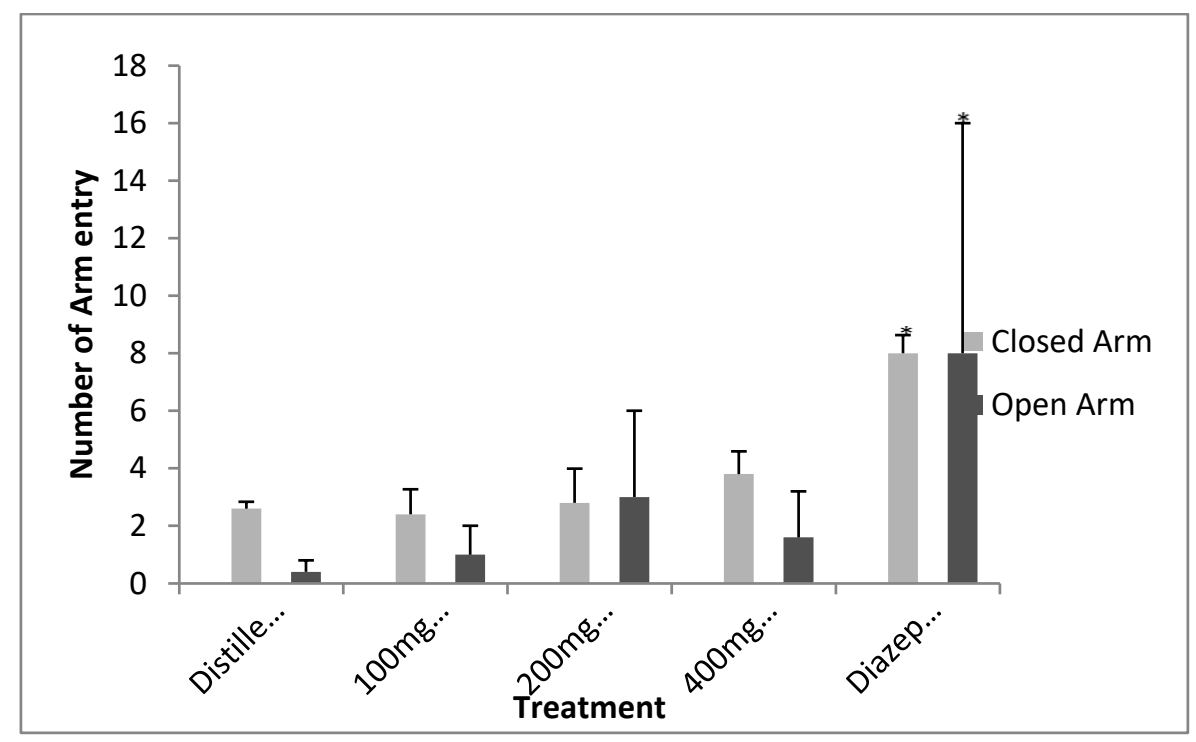

Figure 2 Effect of methanol leaf extract of Cassia singueana on number of entry in closed and open arm of elevated maze plus.

The methanol leaf extract of Cassia singueana has significantly increased the amount of time spent in the open arm at the dose of $200 \mathrm{mg} / \mathrm{kg}$ (Figure 3). 


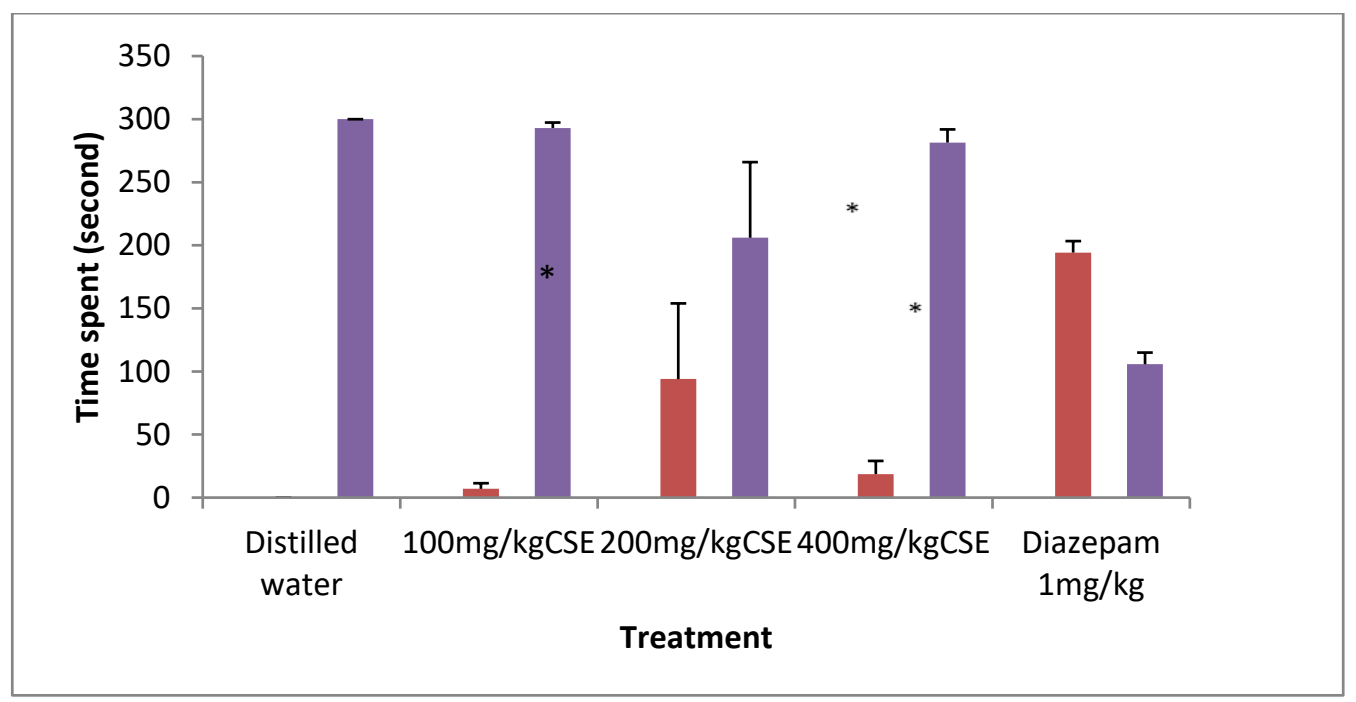

Figure 3 Effect of methanol leaf extract of Cassia singueana on elevated plus maze test using time spent as parameter for determining anxiolytic effect.

The amount of time spent was presented as Mean $\pm \operatorname{SEM} ;(\mathrm{n}=5) .{ }^{*}=\mathrm{p}<0.05$, followed by Dunnet post-hoc

\subsection{Effect of methanol leaf extract of Cassia singueana on open field test for exploratory behavior in mice}

Cassia singueana methanol leaf extract significantly $(\mathrm{p}<0.05)$ increased the number of peripheral square crossing at the dose of 100 and $200 \mathrm{mg} / \mathrm{kg}$ (Figure 4).

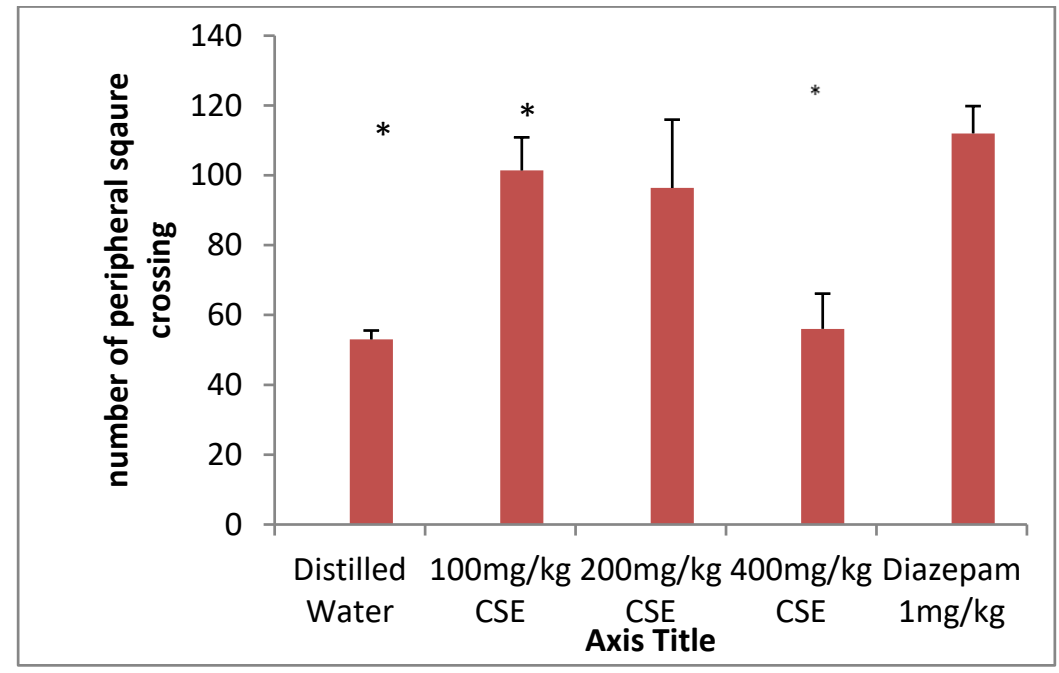

Figure 4 Effect of methanol leaf extract of Cassia singueana on open field test using number of peripheral crossings as parameter for exploratory behavior in mice

The result was presented as Mean \pm SEM; $(n=6){ }^{*}=p<0.05$. Dunnett's post hoc test. CSE- Cassia singueana methanol leaf extract.

There was no significant increase in central square crossing on Open Field test using number of central crossings as parameter for exploratory behavior in mice (Figure 5). 


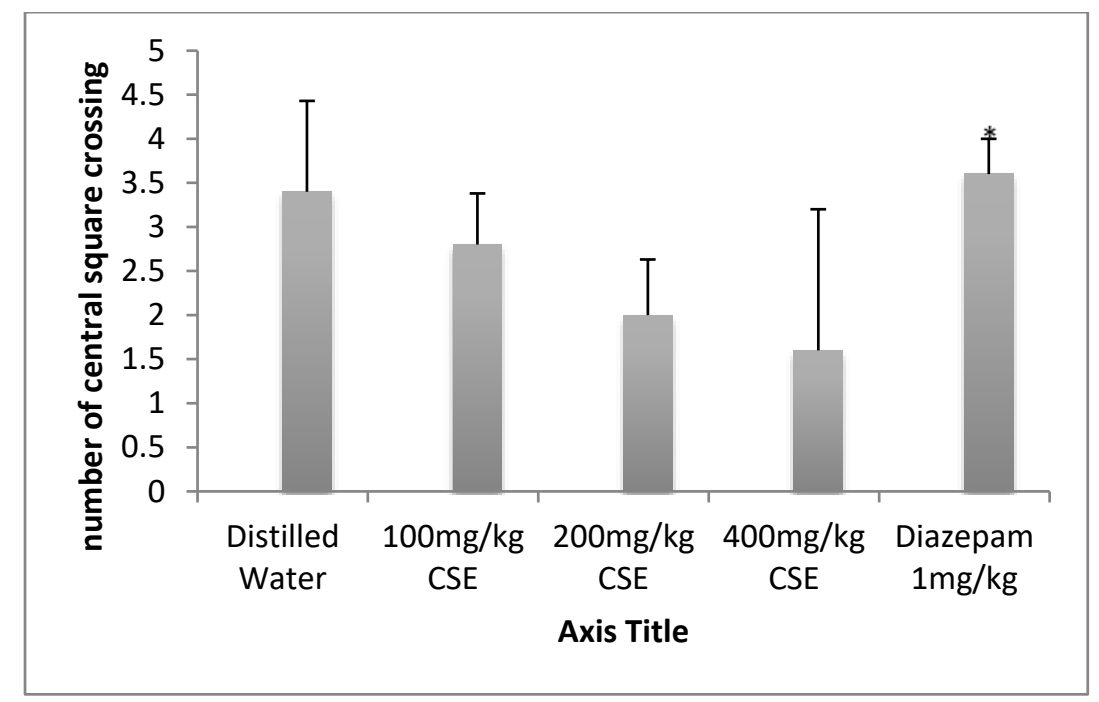

Figure 5 Effect of methanol leaf extract of Cassia singueana on Open Field test using number of central square crossings as parameter for exploratory behavior in mice. The result was presented as mean \pm SEM

\subsection{Force swim test}

The extract at all three doses showed a significant decrease in the duration of immobility in the rats $(\mathrm{p}<0.05)$ when compared with distilled water group (Figure 6).

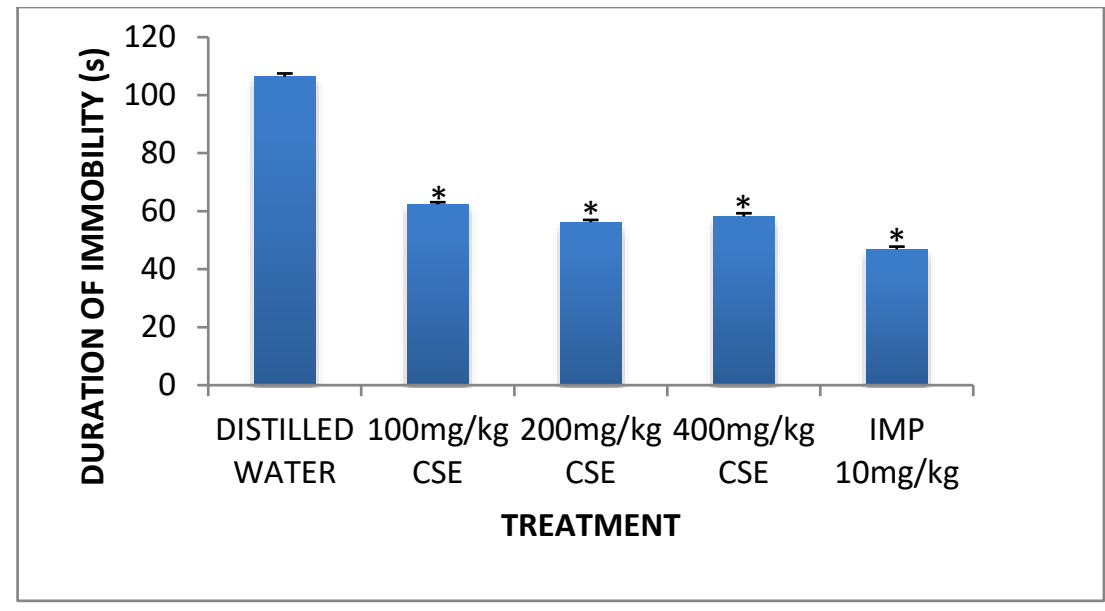

Figure 6 Effect of methanol leaf extract of Cassia singueana on duration of immobility in rats in FST

Results are expressed as mean \pm S.E.M $(n=6){ }^{*}=p<0.05$ as compared to distilled water.

CSE $=$ Cassia singuean $a$ Extract. FST $=$ Forced swim test

\subsection{Tail suspension test}

Cassia singueana at dose of 100, 200 and $400 \mathrm{mg} / \mathrm{kg}$ orally showed significant decrease in the duration of immobility when compared to distilled water treated group (Figure 7). 


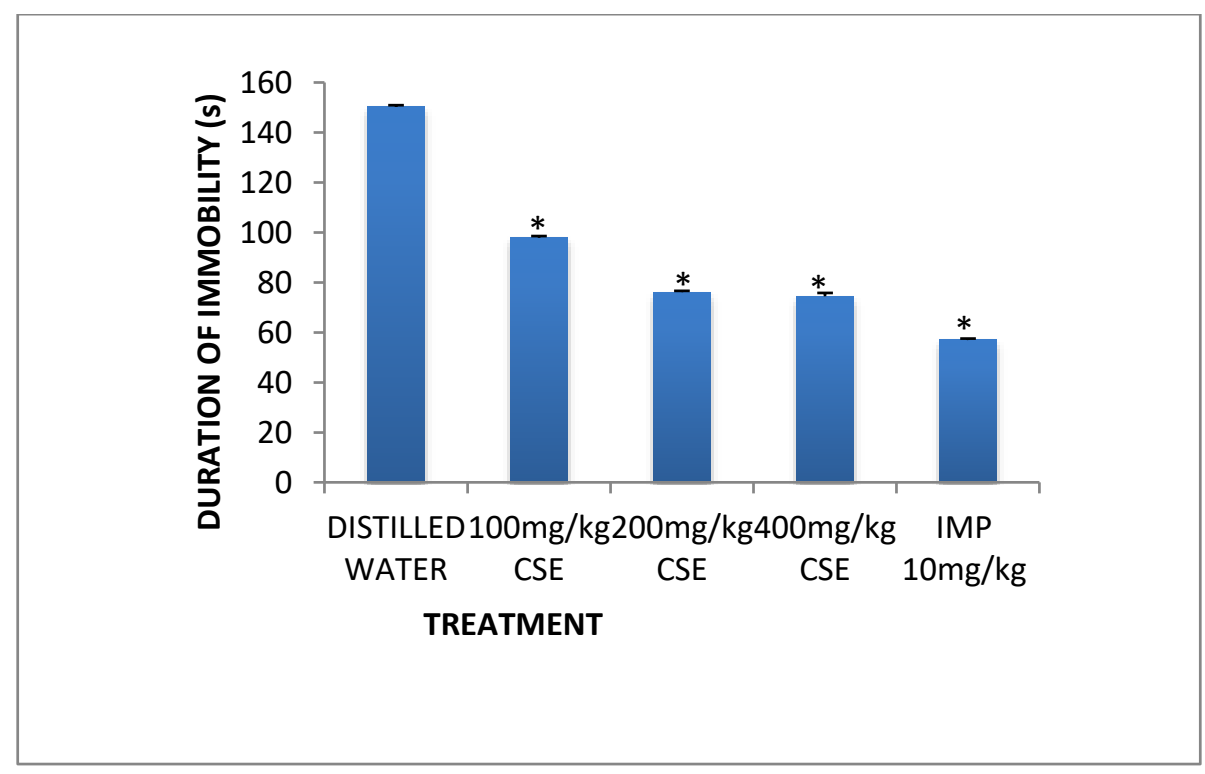

Figure 7 Effect of Cassia singueana on duration of immobility in rats in TST, Duration of immobility is measured in seconds. Results are expressed as mean \pm S.E.M $(n=6) .{ }^{*}=p<0.05$, Dunnet-post hoc.

\section{Discussion}

The methanol leaf extract of Cassia singueana has significantly increased the number of peripheral square crossing and increases the number of head dips indicating enhanced exploratory behavior. It also increases number of entrance in open arm and time spent in open arm, these also suggests an anxiolytic potential. The extract also significantly shortens the duration of immobility in force swim test and tail suspension indicating possible antidepressant activity. The phytochemical screening of the methanol leaf extract of Cassia singueana revealed the presence of tannins, carbohydrates, saponins, flavonoids, steroids, alkaloids and reducing sugar [10]. These phytochemicals present are responsible for these observed activities.

The Open Field test [15], elevated maze plus [13] and hole board test is useful for modeling anxiety in animals [11] [12]. The findings of this study were found to be in agreement with the reports of Jannatun et al [13]. The extract has increase the number of entry in open arm and significantly increase the amount of time spent in the open arm, this indicate possible anxiolytic effect by the extract. The finding was similarly reported by Idris [14]. In the depression studies, the immobility displayed by rats and mice when subjected to unavoidable stress such as Force Swim Test and Tail Suspension Test respectively are thought to reflect state of despair or lowered mood, which is thought to reflect depressive disorders in human [16]

The results obtained in this study showed the reduction in the duration of immobility observed after administering the extract doses to the animals in both models, this indicates possible antidepressant effect the extract. Cassia singueana methanol leaf extract may contain some phytochemicals that enhances the extracellular concentrations of the monoamines such as norepinephrine, epinephrine, dopamine and serotonin by either inhibiting their up-take mechanism or inhibiting their metabolism. There should be further studies on this plant in order to isolate and characterize the active phytochemical(s) responsible for the observed pharmacological activities.

\section{Conclusion}

Cassia singueana methanol leaf extract contain phytochemicals with possible anxiolytic and antidepressant potentials. This study discovered the methanol leaf extract of Cassia singueana contained phytochemicals that can be beneficial for management of depression and anxiety disorder and this study will help the researchers to uncover the critical areas of plant based therapy of anxiety and depression that many researchers were not able to explore. Thus a new theory on pharmacological management of mood disorders may be arrived at. 


\section{Compliance with ethical standards}

\section{Acknowledgments}

Authors acknowledged the effort of whoever participated in accomplishment of this research work.

\section{Disclosure of conflict of interest}

There is no conflict of interest between authors in this research work.

\section{Statement of ethical approval}

The Ethical approval was obtained from the research Ethic Committee of in the department of Pharmacology and toxicology of Usmanu Danfodiyo University, Sokoto.

\section{References}

[1] Rang HP, Dale MM, Ritter JM and Moore PK. (2011). Antidepressant drugs in Rang and Dale's pharmacology, $6^{\text {th }}$ edition, Churchill and Livingstone Elsivier, 400-420.

[2] Craske, MG and Stein MB. (2016). Anxiety. Lancet. Doi:10.1016/S0140-6736(16)30381-6. PMID 27349358.

[3] Barar FSK. (2012). Textbook of Pharmacology. S. Chand Publishing. Drugs Acting on the Central Nervous system. 93.

[4] Kessler RC, Aguilar-G.Slonso J, Lee S and Ustun TB (2007). Lifetime prevalence and age-of-onset distributions of mental disorders in the World Mental Health Survey Initiative. World Psychiatry, 6(3), 168-76.

[5] Kadri N, Agoub M, El Gnaoui S, Berrada S and Moussaoui D.(2007). Prealence of anxiety disorders: A populationbased epidemiological study in metropolitan area of Casablanca, Moracco. Annals of General Psychiatry, 6, 6.

[6] Borwin B and Sophie M. (2015). Epidemiology of anxiety disorders in the $21^{\text {st }}$ century. Dialogues in Clinical Neuroscience, 17(3), 327-335.

[7] Butlet MS. (2004). The role of natural product chemistry in drug discovery. Journal of Natural Products, 67, 214153.

[8] Ahn K. (2017). The worldwide trend of using botanical drugs and strategies for developing global drugs. BMB Reports, 50(3), 111-116.

[9] Porsolt RD, Bertin A, and Jalfre M. (1977). Behavioral despair in mice: a primary screening test for antidepressants. Archives internationales de pharmacodynamie et de therapie, 229, 327-336.

[10] Alkali YI, Abdulgafar OJ, Yerima M and Abubakar K. (2018). Antischizophrenic and central nervous system depressant effects of Cassia singueana. Australian Journal of science and technology, 2, 4.

[11] Crawley JN (1985). Exploratory behavior models of anxiety in mice. Neuroscience and Biobehavioral Reviews, 9 , 37-44.

[12] Takeda H, Tsuji M and Matsumiya T. (1998). Changes in head-dipping behavior in the hole-board Test reflect the anxiogenic and/or anxiolytic state in mice. European Journal of Pharmacology, 13, 50.

[13] Jannatun N, Jasmin AN, Rafat J, Md. Saddam H, Safiqul I and Latifa B. (2016). Screening anxiolytic activities of methanolic fruit extracts of Spondia pinnata Plant. International Research Journal of Pharmacy, 7(11).

[14] Idris AG, Hadiza K, and Sani M. (2018). Anxiolytic-like effect of methanol leaf extract of Laggera aurita Linn. F. (Asteraceae) in mice. Archives of Neuroscience, 5(2).

[15] Treit D, Engin E and McEown K. (2010). Animal models of anxiety and anxiolytic drug action. Current top Behavior Neuroscience, 2, 121-60.

[16] Fujisaki C. (2003). An immnosuppressive drug, cyclosporine-A acts like anti-depressant for rats under unpredictable chronic stress. Journal of Medical and Dental Sciences, 50, 93-100.

[17] Lister RG. (1987). The use of plus-maze to measure anxiety in mice. Psychopharmacology, 92, 180-185. 
Alkali et al. / GSC Biological and Pharmaceutical Sciences 2019, 07(02), 007-015

[18] Kulkarni SK and Reddy DS (1996). Animal's behavioral models for testing antianxiety agent. Method to find exploratory clinical Pharmacology, 18(3), 219-300.

\section{How to cite this article}

Alkali YI, Kabiru A, Yerima M, Aliyu HA, Maryam HG and Fateema YM. (2019). Anxiolytic and antidepressant potential of methanol leaf extract of Cassia singueana f. (fabaceae). GSC Biological and Pharmaceutical Sciences, 7(2), 07-15. 